\title{
Thinned GalnP/GalnAs/Ge solar cells grown with reduced cracking on Ge|Si virtual substrates
}

\author{
Ivan García ${ }^{1 *}$, Laura Barrutia ${ }^{1}$, Shabnam Dadgostar ${ }^{2}$, Manuel Hinojosa $^{1}$, Andrew Johnson $^{3}$ and \\ Ignacio Rey-Stolle ${ }^{1}$ \\ ${ }^{1}$ Instituto de Energía Solar, Universidad Politécnica de Madrid, 28040 Madrid, Spain \\ ${ }^{2}$ GdS Optronlab, Universidad de Valladolid, 47011 Valladolid, Spain \\ ${ }^{3}$ IQE plc, Pascal Cl, St. Mellons, Cardiff, CF3 OLW, United Kingdom
}

\begin{abstract}
Reducing the formation of cracks during growth of GalnP/GalnAs/Ge 3-junction solar cells on Ge|Si virtual substrates has been attempted by thinning the structure, namely the Ge bottom cell and the GalnAs middle cell. The theoretical analysis performed using realistic device parameters indicates that the GalnAs middle cell can be drastically thinned to $1000 \mathrm{~nm}$ while increasing its In content to $8 \%$ with an efficiency loss in the 3 -junction cell below $3 \%$. The experimental results show that the formation of macroscopic cracks is prevented in thinned GalnAs/Ge 2-junction and GalnP/GalnAs/Ge 3-junction cells. These prototype crack-free multijunction cells demonstrate the concept and were used to rule out any possible component integration issue. The performance metrics are limited by the high threading dislocation density over $2 \cdot 10^{7} \mathrm{~cm}^{-2}$ in the virtual substrates used, but an almost current matched, crack-free, thinned 3-junction solar cell is demonstrated, and the pathway towards solar cells with higher voltages identified.
\end{abstract}

\section{Introduction}

The development of high efficiency III-V multijunction solar cells monolithically grown on silicon substrates is challenged by the large lattice mismatch and dissimilar thermal expansion coefficients between the III-V and Si materials, which causes the formation of cracks in the epilayers. Using compositionally graded buffers (CGB) has been demonstrated to be a way to achieve reduced threading dislocation densities (TDD) with GaAsP [1]-[4] and SiGe [5]-[8] based structures, mainly. However, the thickness added to the structure by the CGBs makes it difficult not to surpass the critical thickness for crack propagation, experimentally observed to be around $5 \mu \mathrm{m}$ for III-V on Si at typical growth temperatures [9]. Crack-free GaInP/GaAs/Si solar cells grown monolithically using GaAsP CGBs have been reported [10]. Due to the slightly higher than optimal bandgap of $\mathrm{Si}$, this approach requires thinning the upper subcells to achieve current matching and maximizing the efficiency, which, at the same time, makes possible to prevent cracking.

In a parallel approach under development, TDD of $1-5 \cdot 10^{6} \mathrm{~cm}^{-2}$ have been achieved with direct growth of Ge on Si [11]-[13]. This approach has the advantage of allowing the direct integration of already developed high efficiency solar cell structures based on Ge or GaAs substrates. In fact, promising results have been demonstrated for GaAs and GalnP singlejunction solar cells [14]-[16]. For higher efficiency, thicker structures and more junctions are needed, and thus various approaches have been tested to reduce the formation of cracks. Scaccabarozzi et al. used coalesced Ge layers on deeply patterned Si substrates, with the surface morphology improved through chemical mechanical polishing (CMP). With this method, they attained GalnP/GalnAs/Ge|Si triple-junction solar cell (3JSC) exhibiting an external quantum efficiency (EQE) comparable to the samples grown on standard Ge substrates, but with a significant voltage loss attributed to an imperfect growth on the coalesced Ge template. Bioud 
et al. used embedded nanovoids at the Ge|Si interface by electrochemical porosification plus annealing, to achieve lower TDD, but which could be used also for reduced cracking [17]. Another approach by Oh et al. consisted on inducing the geometrically controlled formation of cracks by a notch pattern applied to the Si substrate, strategically arranged to enable the fabrication of the solar cell devices in the resulting crack-free regions [18]. All these methods intend to control the formation of cracks in structures over the critical thickness, so that their effect on the active regions of the solar cells is limited. This has the advantage of decoupling the strategy to mitigate the effect of the cracks from the design of the solar cells. On the other hand, the modifications to the substrate required, often involving nanopatterning, add complexity to the fabrication process, which could hinder the application to mass production scenarios.

Conversely, the approach that we investigate in this work pursues limiting the formation of cracks by redesigning the solar cell structure, in the context of GalnP/GalnAs/Ge 3JSC. In our previous works, we showed that standard 3JSC structures (over 6 micron thick) could be grown on $\mathrm{Ge} \mid \mathrm{Si}$ templates with a $5 \mu \mathrm{m}$ thick Ge layer, but the formation of cracks contributed to the low performance of the solar cells fabricated [19], [20]. In this work we analyze the thinning of the 3JSC structure to reduce the formation of cracks. Firstly, we use thinner Ge layers of $3 \mu \mathrm{m}$ in the Ge|Si template, which are enough to produce the required photocurrent for a currentmatched 3JSC [19]. Then, we test the effect of aggressively reducing the thickness of the GalnAs middle cell. A side benefit is that the lower recombination volume allows to obtain higher voltages in these thinned solar cells grown on Ge|Si templates. However, this thinning causes a reduction in the photocurrent of the middle cell, losing the current-matching condition in the 3JSC. Adding a distributed Bragg reflector (DBR) below the GalnAs middle cell, similarly as in space solar cell applications to increase the radiation hardness of the cells [21], would only allow thinning this subcell to about $2500 \mathrm{~nm}$ without photocurrent losses, and the added thickness by the DBR would defeat the objective of achieving a globally thinner structure. A different approach is followed in this work: the reduction of the middle subcell bandgap to increase its photocurrent is explored theoretically and demonstrated experimentally to allow regaining current matching in the 3JSC. The voltage reduction due to the lower bandgap in the GalnAs subcell represents a significantly lower loss for the 3JSC performance than the effect of the current mismatch when this subcell is only thinned without changing its bandgap. Nevertheless, this voltage drop represents a performance loss in comparison to the standard 3JSC. The tradeoff between the advantages of using Ge|Si substrates (lower usage of Ge, potential lower cost, possibility of substrate detachment using embedded porous layers [19], [20], etc) and the lower efficiency will determine the economic viability of this approach.

In this paper we first present a theoretical assessment of the effects of thinning the structure on the performance of a 3JSC, and the potential of using a lower bandgap in the middle cell to mitigate the associated losses. Then we present the experimental results obtained with thinned GalnAs middle cells grown on Ge|Si virtual substrates, compared to those grown on standard Ge substrates. By increasing the In content in this subcell we show that the photocurrent of the thinned subcell can be recovered, at the expense of some voltage loss. Finally, we implement a proof-of-concept 3JSC, including the thinned GalnAs subcell, which shows no significant cracking and no component integration issues.

\section{Methods}

The fit to the experimental EQE and calculation of the short circuit current densities $\left(\mathrm{J}_{\mathrm{sc}}\right)$ is performed using the Scattering Matrix Method [22] and Hovel models, with initial minority carrier parameters measured previously in our structures [23]. The calculation of the open circuit voltages $\left(V_{o c}\right)$ for the GalnAs subcells with different In contents, discussed in Section 3, 
was performed following the model by Steiner et al. in [24]. The inputs to this model are the optical properties of the semiconductor stack, the EQE and the internal luminescence efficiency $\left(\eta_{\text {int }}\right)$, which defines the ratio of global radiative to total recombination in the absorber (emitter + base) and represents the electronic quality of the material. Values of $\sim 0.4$, observed in our standard GalnAs solar cells, are used. This $\eta_{\text {int }}$ value is higher than expectable for the so far lower quality cells grown on Ge|Si substrates, but the theoretical study presented here intends to analyze the potential performance variations of the cells when redesigned by changing their thickness and bandgap, assuming at least the same minority carrier properties as in cells grown on standard Ge substrates. Note that this model captures the decrease in $\mathrm{V}_{\mathrm{oc}}$ as the bandgap decreases and also as the absorber thickness increases, due to a higher recombination in the volume [24]. As will be discussed later, this effect will play a significant role in determining the voltage loss as the solar cell bandgap and thickness are redesigned. The $\mathrm{J}_{\mathrm{sc}}$ calculation from EQE data is performed using the AM1.5G spectrum $\left(1000 \mathrm{~W} / \mathrm{m}^{2}\right)$. The trends obtained for the direct and $\mathrm{AMO}$ spectrum are analogous.

The Ge|Si virtual substrates were fabricated at IQE PLC using silicon substrates with a miscut of 60 towards the nearest (111) plane. The Ge layers were deposited by CVD as explained elsewhere [19]. In this work, virtual substrates with a $3 \mu \mathrm{m}$ thick Ge layer are used, as compared to our previous reports for $5 \mu \mathrm{m}$ thick Ge layers [19], [20]. These thinner Ge subcells were experimentally confirmed to achieve the required $J_{s c}$ for the 3JSC application. The virtual substrates used exhibit a threading dislocation density (TDD) of $\sim 2 \cdot 10^{7} \mathrm{~cm}^{-2}$, measured by planview cathodoluminescence mapping $(\mathrm{CL})$ of GalnAs overbuffer layers grown on them. For comparison, standard Ge substrates were also used. They were p-type doped with Gallium and again with a miscut of 60 towards the nearest (111) plane. The III-V epistructures were grown in a research-scale, horizontal, low-pressure AIX200/4 reactor, using $\mathrm{AsH}_{3}, \mathrm{PH}_{3}, \mathrm{TMGa}$, TMIn, TMAl, DMZn, DTBSi and DETe as precursor molecules. The growth rates used vary from 2 to $4 \mu \mathrm{m} / \mathrm{hr}$ and the growth temperature is $675^{\circ} \mathrm{C}$ for phosphides, $640^{\circ} \mathrm{C}$ for arsenides and $550^{\circ} \mathrm{C}$ for tunnel junctions. The 3JSC structure used is depicted in Figure 1. Further details of these baseline structures can be found elsewhere [25]. In this work we use the same growth conditions for the structures grown on $\mathrm{Ge} \mid \mathrm{Si}$ as in our standard structures on Ge substrates. Reducing the growth temperature has the potential of reduce cracking, and it is planned to be studied in future works.

The lattice-constants and compositions in the structures grown were characterized by High Resolution X-Ray Diffraction (HRXRD) using an X'Pert Panalytical MRD diffractometer with the Xray beam conditioned using a $4 \times G e(220)$ monochromator, to obtain rocking curves and reciprocal space maps (RSM). Cathodoluminescence $(C L)$ measurements were taken using a LEO 1530 (Carl-Zeiss) field- emission scanning electron microscope (FESEM) equipped with a MonoCL2 (Gatan UK) CL system. Panchromatic images were recorded with a photomultiplier tube (PMT) for the visible range, and with an InGaAs detector for the near infrared. The images were acquired for different e-beam energies, from $5 \mathrm{keV}$ to $25 \mathrm{keV}$, to reveal the defects of the different layers forming the structure. All the measurements were done at $80 \mathrm{~K}$ to enhance the $\mathrm{CL}$ emission intensity.

Solar cell manufacturing is based on standard photolithography techniques for the definition of the front grid, which is based on the AuGe/Ni/Au system. An inverted square geometry is used for the front grid, with an active area of $0.1 \mathrm{~cm}^{2}$. The back contact is based on gold for solar cells fabricated on Ge substrates, and $\mathrm{Pd} / \mathrm{Ti} / \mathrm{Pd} / \mathrm{Al}$ for cells fabricated on Si/Ge virtual substrates, which allows obtaining high performance contacts to the Si substrate without applying detrimental thermal loads to the III-V structure [26].

EQE and reflectivity (R) were measured using a custom-built system based on the lock-in technique to detect the photocurrent of the solar cell excited by monochromatic light obtained 
using a Xe lamp and a grating monochromator. A monitor cell is used to compensate for fluctuations in the Xe-lamp. I-V curves were obtained using a Xe-lamp solar simulator and a 4quadrant Keithley source-monitor unit. Finally, bandgap variations were measured by spectral electroluminescence (EL) in the 300-1100 nm range using a calibrated fiber spectrometer based on a silicon CCD detector. For the Ge subcells, the bandgap is assumed to be $0.65 \mathrm{eV}$.

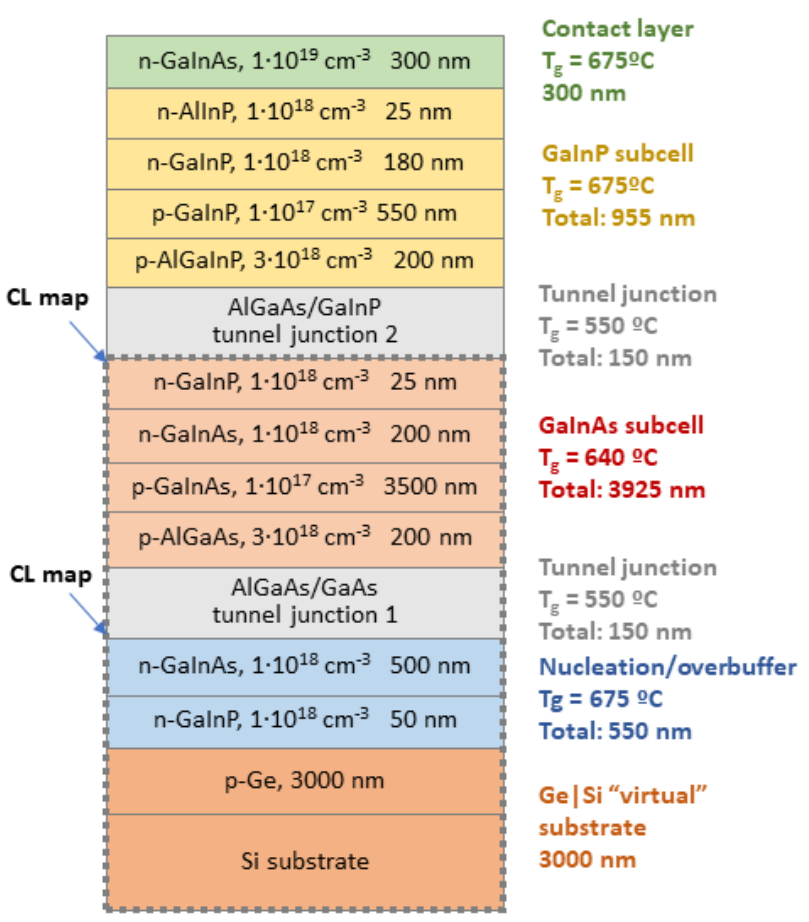

Figure 1. Structure of the baseline 3JSC grown on a Ge|Si virtual substrate. The dashed line frame indicates the GalnAs/Ge double-junction solar cell (2JSC) structure that is redesigned along this work. The arrows indicate where $\mathrm{CL}$ maps were taken to quantify the TDD mentioned along this paper.

\section{Theoretical analysis.}

The proposed approach based on thinning and increasing the indium content of the GalnAs subcell allows to substantially reduce the thickness of the 3JSC structure but at the same time reduces the $V_{o c}$ of the GalnAs subcell, due to its lower bandgap. Besides, the lower bandgap in this subcell implies less spectral range available to the Ge bottom cell. We quantify these two effects with this theoretical study. A GalnP top cell grown lattice-matched to the metamorphic GalnAs subcell with higher indium content as in upright metamorphic 3JSC designs [27], would have a lower bandgap than GalnP lattice-matched to $\mathrm{Ge}$, which implies an additional $\mathrm{V}_{\text {oc }}$ loss in the 3JSC. This can be mitigated by using AIGalnP instead, in view of the excellent photovoltaic quality obtained by other authors in single [28] and multijunction solar cells [29]. Therefore, in our theoretical study, the bandgap of the top cell is assumed to have its usual value for standard lattice-matched 3JSC designs.

The $J_{s c}$ of the GalnAs and Ge subcells in a 3JSC, and the $V_{o c}$ of the GalnAs subcell were computed for a range of GalnAs subcell base layer thicknesses and In contents. The effect of the In content on the absorption coefficient is estimated using an square root model applied to the fitted GaAs data [30]. The results shown in Figure 2-A illustrate the change in the EQE of the middle and bottom subcells as the GalnAs base layer thickness and bandgap are decreased. Graphs B to D are contour plots of parameters vs the GalnAs subcell thickness and In 
composition. The GalnAs subcell $\mathrm{J}_{\mathrm{sc}}$ shown in graph $\mathrm{B}$ clarifies the amount of In to add to the GalnAs material to keep the $J_{s c}$ constant as its thickness is decreased. The noticeable transition from a slower to a higher increase rate of the In content required as the thickness is decreased takes place when the GalnAs subcell bandgap and EQE low energy edge enters one of the characteristic dips in the solar spectrum (see graph A). In fact, this inflexion point is not present for the AMO spectrum (not shown), for which lower In contents are required to maintain the JsC in thinned GalnAs subcells. Around 8\% ( $0.5 \%$ lattice mismatch to the Ge substrate) In content is required for a thickness of $1000 \mathrm{~nm}$ (compared to $\sim 1 \%$ In for the optically thick $3500 \mathrm{~nm}$ baseline). This low In content should not be a problem to produce high photovoltaic quality material. The method used to implement this GalnAs composition is presented in Section 4.2.

Figure 2-C shows the evolution of the $\mathrm{J}_{\mathrm{sc}}$ in the Ge subcell, revealing the expected opposite behaviour as compared to the GalnAs subcell: the thinner and lower In content in the GaInAs, the more photons are transmitted to the Ge junction and the higher is its $\mathrm{J}_{\mathrm{sc}}$. Besides, the shape of the contours expose and interesting effect: the $J_{s c}$ of the Ge subcell decreases even if the $J_{s c}$ of the GalnAs subcell is kept constant as the thickness and In content change simultaneously, as occurs by following the iso- $\mathrm{J}_{\text {sc }}$ dashed line. In fact, the standard 3JSC structure used as baseline in this study is designed with an optically thick GalnAs subcell, and with other GalnAs layers underneath, including the tunnel junction and overbuffer (see Figure 1). As the GalnAs subcell is made thinner, these other GaInAs layers underneath start to parasitically absorb photons, explaining the $J_{s c}$ decrease in the Ge bottom cell. In any case, the $J_{s c}$ in the Ge subcell for the $1000 \mathrm{~nm}$ and $8 \%$ In content GalnAs subcell is over $18 \mathrm{~mA} / \mathrm{cm}^{2}$, which is higher than required for a current-matched 3JSC $\left(\sim 15.1 \mathrm{~mA} / \mathrm{cm}^{2}\right)$, although the effect of dislocations in Ge subcells fabricated with Ge|Si virtual substrates is expected to reduce this $J_{s c}$ excess [19].

Finally, the calculated $V_{o c}$ in the GalnAs subcell for higher In content and thickness can be observed in Figure 2-D. Some relevant $V_{\text {oc }}$ variations from this contour plot are summarized in Table 1. The $V_{o c}$ drop when increasing the In concentration from $1 \%$ to $8 \%$ (for constant thickness), is estimated to be $94 \mathrm{mV}$. If the thickness is reduced as needed to keep the $\mathrm{J}_{\mathrm{sc}}$ constant, the $V_{o c}$ drop decreases to $70 \mathrm{mV}$, i.e., the $V_{o c}$ recovers partially as the base layer is made thinner. It is important to point out that, as detailed in the Methods section, this study assumes a $\eta_{\text {int }}$ of 0.4 , which corresponds to our standard material quality but it is low as compared to state-of-the art GaAs [31]. With a higher $\eta_{\text {int, }}$ the effect of thickness would be lower. However, despite the best TDD achieved in Ge|Si virtual substrates is in the $1-5 \cdot 10^{6} \mathrm{~cm}^{-2}$ range and with expectations to obtain even lower values, some effect of the TD on the $\eta_{\text {int }}$ is likely. Previous analysis on high quality metamorphic GalnAs with TDD values in this range showed $\eta_{\text {int }}$ of 0.3-0.6 at 1-sun current levels [32]. Therefore, we can consider the $V_{o c}$ drop estimation obtained here as good estimation for GalnAs cells grown on Ge|Si virtual substrates with the TDD range considered. However, note that, as will be shown in next sections, the effect of thickness on the $V_{\text {oc }}$ of the experimental GalnAs subcells studied here largely exceeds these estimations due to the higher TDDs in the Ge|Si virtual substrates used in this work.

In summary, thinning and increasing the In content in the GalnAs subcell will produce an estimated $V_{\text {oc }}$ loss of $70 \mathrm{mV}$ in the 3JSC. This represents a relative $\sim 3 \%$ lower efficiency at 1 sun and relative $2 \%$ for high concentration (1000 suns and assuming an ideality factor of 1 in all junctions to extrapolate the $V_{\text {oc }}$ to this concentration). The effect of the TDD, inherent to the use of $\mathrm{Ge} \mid \mathrm{Si}$ virtual substrates, can produce additional $\mathrm{V}_{\text {oc }}$ losses. For the $1 \cdot 10^{6} \mathrm{~cm}^{-2} \mathrm{TDD}$ range, $\mathrm{V}_{\text {oc }}$ drops of $70 \mathrm{mV}$ have been reported in GaInP/GaAs 2JSC with usual thicknesses, being the GaAs subcell responsible for $\sim 60 \mathrm{mV}$ [33]. Note however that our thinned GalnAs subcell would be less affected by the TD and, therefore, the $V_{\text {oc }}$ drop would be lower. No estimations of the effect of the TD on the Ge subcell, which is also affected by misfit dislocations, are available, but the experimental results on highly dislocated Ge|Si virtual substrates, compared to standard Ge 
substrates (shown in Section 4.1, Table 3), indicates that this subcell can contribute with a few tens of $\mathrm{mV}$ more to the losses. Therefore, the effect of TDD in the $1.10^{6} \mathrm{~cm}^{-2}$ range can account for a significant increase in the $\mathrm{V}_{\text {oc }}$ loss but they can be minimized as long as better quality $\mathrm{Ge} \mid \mathrm{Si}$ substrates are achieved, conversely to the impact of redesigning the structure on the $V_{\text {oc }}$ that is inevitable. Eventually, the aggregated economic benefits of using high quality $\mathrm{Ge} \mid \mathrm{Si}$ substrates must be higher than the losses produced by a $2-3 \%$ lower efficiency, to make this approach economically viable, which seems feasible.
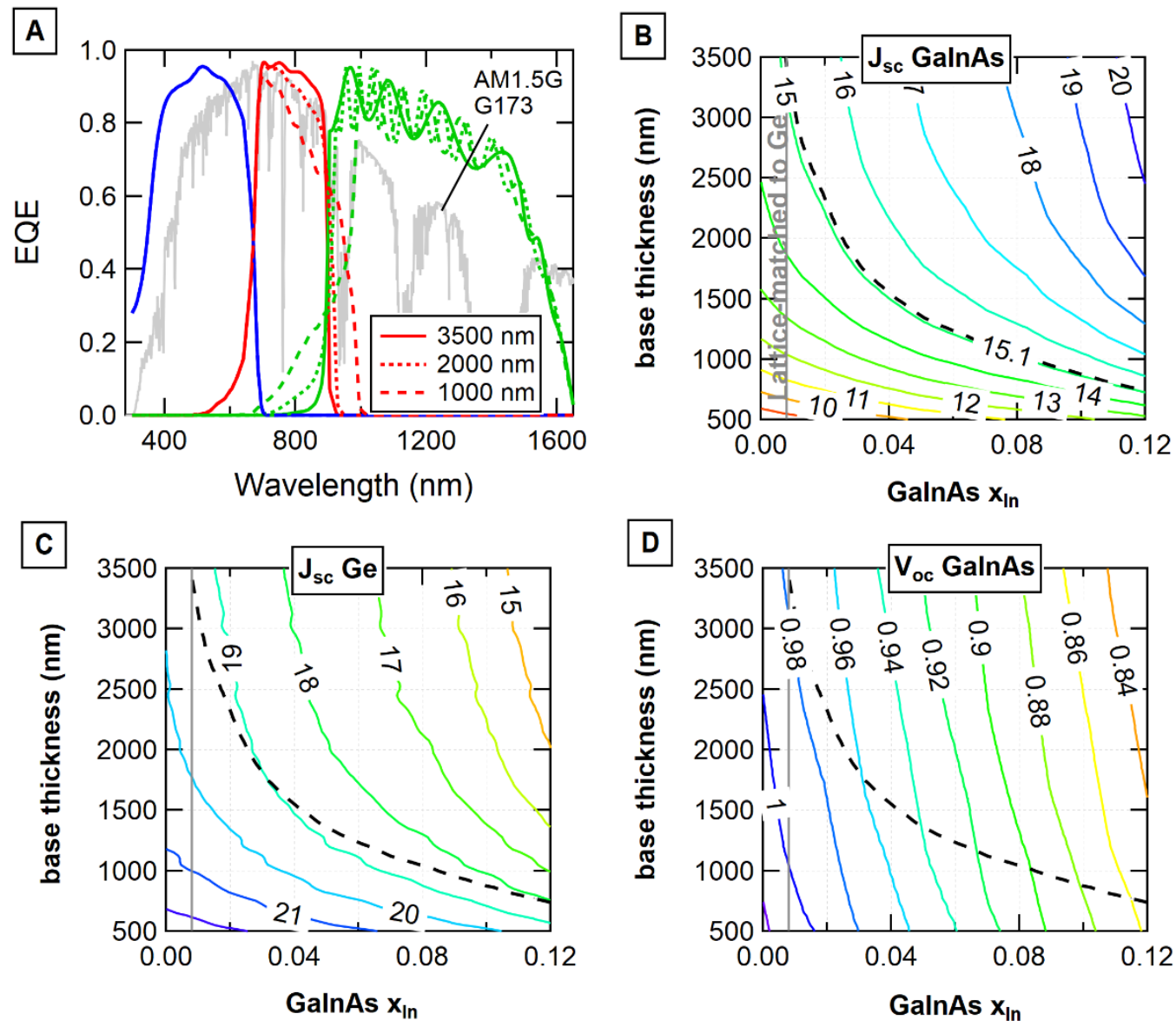

Figure 2. $\underline{A}$ : modeled EQE of the 3JSC subcells, for three GalnAs base thicknesses and In compositions that produce current matching with the top GalnP subcell. The grey curve is the AM1.5G solar spectrum in arbitrary units. $\underline{B}$ to $\underline{D}$ : $J_{s c}$ of the GalnAs subcell, $J_{s c}$ of the Ge subcell and $V_{o c}$ of the GalnAs subcell vs its base thickness and In composition. The dashed black lines in graphs $\underline{C}$ and $\underline{D}$ are the iso-contour of GalnAs subcell $\mathrm{J}_{\mathrm{sc}}$ at the value obtained for the standard case. The solar cells have a $\mathrm{MgF}_{2} / \mathrm{ZnS}(85 / 40$ $\mathrm{nm})$ anti-reflection coating that optimizes the $\mathrm{J}_{\mathrm{sc}}$. The AM1.5G $\left(1000 \mathrm{~W} / \mathrm{m}^{2}\right)$ solar spectrum is used in all cases.

\begin{tabular}{|c|c|c|}
\hline \multirow{2}{*}{$\begin{array}{c}\text { GaInAs } \\
\% \text { In }\end{array}$} & $\begin{array}{c}\text { GalnAs base } \\
\text { thickness } \\
\text { (nm) }\end{array}$ & $\begin{array}{c}\Delta \mathbf{V}_{\text {oc }} \\
(\mathbf{m V} \mathbf{)}\end{array}$ \\
\hline \multirow{3}{*}{1.00} & 3500 & 0 \\
\cline { 2 - 3 } & 2000 & +12 \\
\cline { 2 - 3 } & 1000 & +23 \\
\hline \multirow{2}{*}{8.00} & 3500 & -94 \\
\cline { 2 - 3 } & 2000 & -82 \\
\hline
\end{tabular}




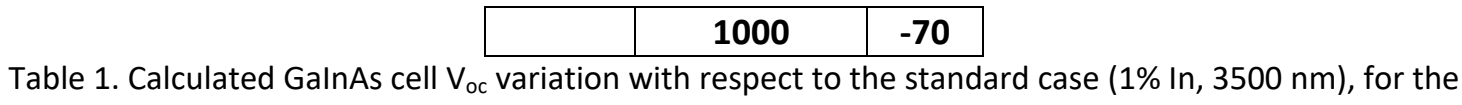
In contents and thicknesses explored. The target GalnAs subcell design is highlighted in bold.

\section{GaInAs subcell experimental results.}

As commented before, the GalnAs subcell is the thickest component of the 3JSC structure and, therefore, a target in our efforts to reduce the total thickness and prevent cracking. To this end, GalnAs/Ge double-junction solar cells (2JSC) were grown, processed and characterized to examine the effect of thinning the base layer and changing its bandgap by increasing the In content.

\subsection{Effect of thinning the base layer.}

We first focus on the effect of thinning the base layer of the GalnAs subcells grown on $\mathrm{Ge} \mid \mathrm{Si}$ virtual substrates. Using the baseline structure shown in Figure 1, GalnAs/Ge 2JSC were grown with different base layer thicknesses while keeping the rest of the structure nominally identical, and solar cells were fabricated with these structures. The EQE of these solar cells is shown in Figure 3, which also includes the case of a 3500 and $1000 \mathrm{~nm}$ base layer thickness for GalnAs cells grown on a Ge substrate, as a reference. The EQEs of the cells grown on a Ge substrate were fitted and the obtained parameters were used for the initial fitting of the cells grown on Ge|Si. A summary of the extracted diffusion lengths is shown in Table 2, as well as the $J_{s c}$ calculated using these EQE with $700 \mathrm{~nm}$ as high energy cut-off, emulating the presence of a GalnP top cell as in a 3JSC. Figure 3 also includes two representative Nomarski microscope images of structures grown on Ge |Si corresponding to 3500 and $1000 \mathrm{~nm}$ base layer thicknesses, which show a high density of cracks in the thick structure, and no cracks present in the thin case

First, a significant reduction in the carrier collection efficiency, and modeled diffusion lengths, can be observed when comparing the solar cells with standard thickness grown on Ge and Ge|Si substrates. The high TDD in the Ge|Si templates used can justify this. On the other hand, the higher diffusion length observed as the base layer is thinned in the GalnAs subcells grown on Ge|Si substrates was unexpected. To further investigate this finding, $\mathrm{CL}$ maps were taken on the samples with 1000 and $3500 \mathrm{~nm}$ base thicknesses for two cases: first, structures with only the top contact layer etched, and second, with all the layers etched down to the GalnAs overbuffer (measurement positions indicated with arrows in Figure 1). The resulting $\mathrm{CL}$ images for the $3500 \mathrm{~nm}$ thick base cell are shown in Figure 3. Firstly, the CL map for the GalnAs overbuffer shows the TD in a density of $\sim 2 \cdot 10^{7} \mathrm{~cm}^{-2}$, with no other remarkable feature. However, the $\mathrm{CL}$ map taken at the top of the GalnAs cell shows an unexpected array of misfit dislocations. All the layers in these structures are lattice-matched to $\mathrm{Ge}$, as corroborated by HRXRD RSM. It seems that the TD coming from the substrate, or new TD, glide during the growth of the GalnAs subcell, generating misfit dislocations (MD). The driving force for this dislocation movement is not certain, but thermal strain, due to the thermal mismatch between $\mathrm{Si}$ and the rest of the structure, is the expected cause. The Ge|Si template fabrication includes thermal cycling (at temperatures higher than used for the growth of the III-V structure) for the minimization of the TDD. However, as thickness is added to the structure during the growth of the solar cells, additional thermal strain can be originated, and drive the movement and/or nucleation of existing TD. The CL maps for the $1000 \mathrm{~nm}$ base layer cell showed a similar TDD in the overbuffer layer and misfit array density in the GalnAs (not shown in Figure 3). For the CL beam energy used, the scan integrates a depth of $700 \mathrm{~nm}$. Therefore, it appears that the formation of misfits starts for as thin GalnAs layers as $<1000 \mathrm{~nm}$. Concerning the possible role of cracks, as the base thickness is reduced, the crack density (summarized in Table 2) decreases, with only a few cracks at the very edges of the 4" wafers observed for the thinnest samples (achieving the primary objective of this study). The effect of the macroscopic cracks on the carrier collection should be 
limited for the crack densities measured but it is reasonable to expect the presence of related defects (microcracks for example), which could have an impact on the EQE, but are removed as the structure is thinned. This can explain the higher carrier collection efficiencies for thinner GalnAs samples. At any rate, beyond the elimination of cracks that is demonstrated for the thinned samples, it seems obvious that the unexpected formation of MD in the active layers must be prevented. We expect that using Ge|Si substrates with a lower TDD will be decisive in this respect.
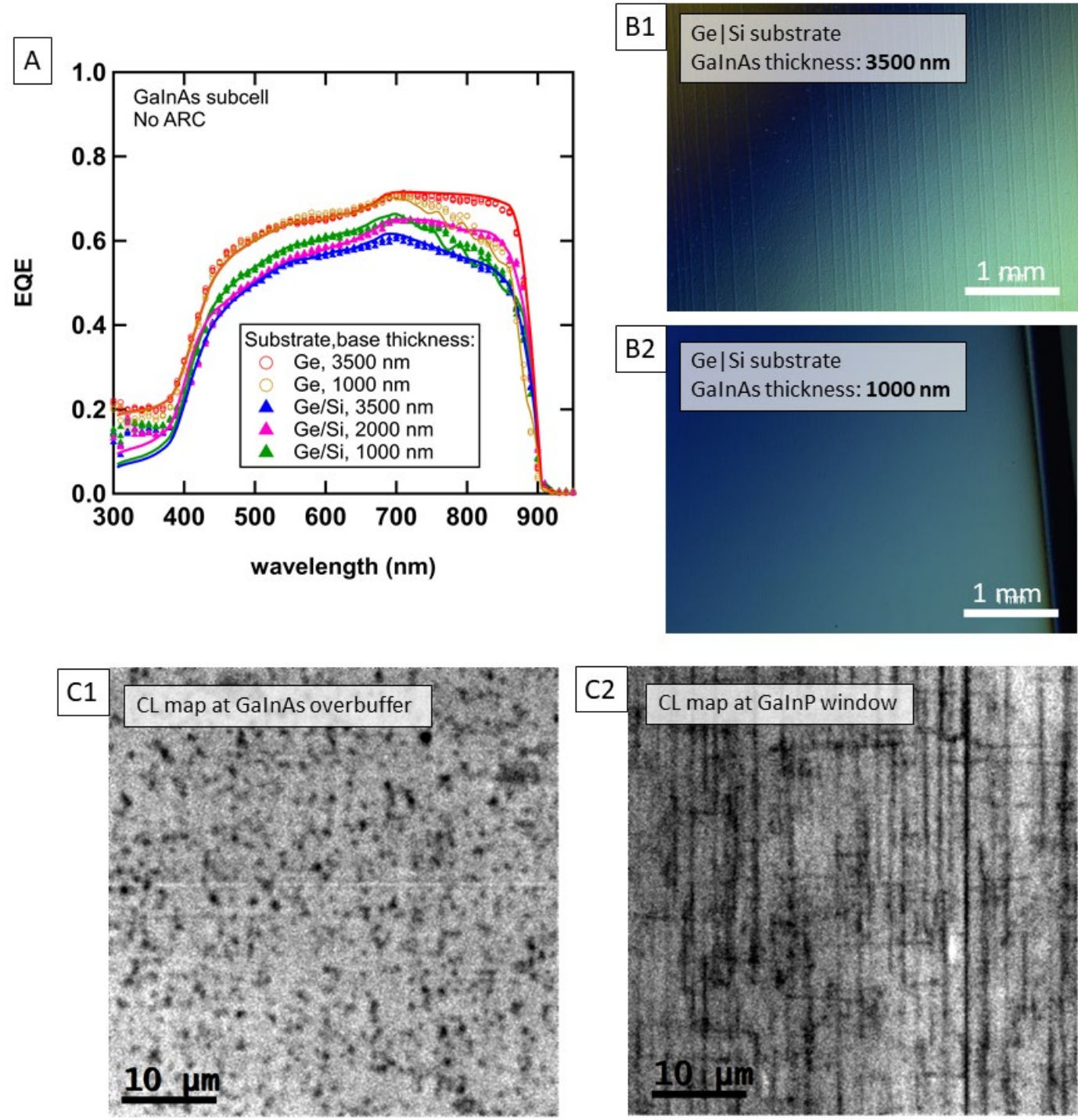

Figure 3. $\underline{A}$ : EQE of lattice-matched ( $1 \% \ln )$ GalnAs subcells grown on Ge and Ge|Si virtual substrates with different base thickness. Symbols: experimental; lines: fit using Hovel model. B1-2: Nomarski images of the sample surface for the standard (B1) and thinned (B2) structures grown on Ge|Si substrates. C1-2: CL map images (taken at $10 \mathrm{keV}$ ) of the cell structure with a $3500 \mathrm{~nm}$ base layer taken at the GalnAs overbuffer (C1) and GalnP window layer of the GalnAs middle cell (C2). 


\begin{tabular}{|c|c|c|c|c|c|c|}
\hline Substrate & $\begin{array}{l}\text { Base thickness } \\
\text { (nm) }\end{array}$ & $\% \ln$ & $\begin{array}{l}\text { Lh,emitter } \\
\text { ( } \mu \mathrm{m})\end{array}$ & $\begin{array}{l}L_{e, b a s e} \\
(\mu \mathrm{m})\end{array}$ & $\begin{array}{c}\mathrm{J}_{\mathrm{sc}}(>700 \mathrm{~nm}) \\
\left(\mathrm{mA} / \mathrm{cm}^{2}\right)\end{array}$ & $\begin{array}{c}\text { average } \\
\text { cracks/mm }\end{array}$ \\
\hline \multirow{2}{*}{$\mathrm{Ge}$} & 3500 & 1 & 2.0 & 20.0 & 8.7 & 0 \\
\hline & 1000 & 1 & 2.0 & 20.0 & 7.8 & 0 \\
\hline \multirow{4}{*}{$\mathrm{Ge} \mid \mathrm{Si}$} & 3500 & 1 & 0.3 & 1.8 & 6.9 & $>5$ \\
\hline & 2000 & 1 & 0.3 & 5.1 & 7.9 & $0-5$ \\
\hline & 1000 & 1 & 0.4 & 16.1 & 7.4 & $\sim 0$ \\
\hline & 1000 & 6.7 & 0.4 & 2.0 & 8.5 & $\sim 0$ \\
\hline
\end{tabular}

Table 2. Summary of minority carrier diffusion lengths, $\mathrm{J}_{\mathrm{sc}}$ and crack density of the samples presented along this work. Lh,emitter/base : diffusion lengths of minority carriers in the emitter (holes) and base (electrons) obtained by fitting the EQE curves in Figure 3 (for GalnAs with $1 \%$ In) and Figure 6 (for GalnAs with $6.7 \% \mathrm{In}$ ). The $\mathrm{J}_{\mathrm{sc}}$ was calculated using the AM1.5G spectrum and the EQE for a high energy cut-off of $700 \mathrm{~nm}$. The rightmost column shows the average linear density of cracks measured.

Light J-V curves of the GalnAs/Ge 2JSC were measured on a statistically significant number of devices and are shown in Figure 4 . The multiple lines with same color in Figure 4 give a visual idea of device-to-device variability. The dispersion observed is partly caused by a different metal shadowing in the devices (varied number of fingers in the front contact, including devices with no fingers for the EQE measurements). The $V_{o c}$ and $W_{o c}$ (difference between $V_{o c}$ and bandgap) obtained are summarized in Table 3. The $V_{o c}$ of the Ge subcells shown in Table 3 was measured by first etching the top GalnAs junction and then processing the Ge cells as single-junction devices. The relatively low $V_{o c}$ measured in the Ge subcell fabricated with standard Ge substrates is caused by the thermal load applied during the growth of the rest of the structure, which degrades the emitter and front surface minority carrier properties of the Ge junction [34]-[36]. However, the difference in thermal load between the 2JSC with 3500 and $1000 \mathrm{~nm}$ base thickness in the GalnAs subcell was observed to cause variations in the $V_{\text {oc }}$ of less than $5 \mathrm{mV}$, and therefore are neglected in this study for simplicity.

As expected, the $\mathrm{J}_{\mathrm{sc}}$ in the cells grown on standard Ge substrates decreases significantly when decreasing the absorber thickness from 3500 to $1000 \mathrm{~nm}$, in agreement with the EQE (Figure 3). A noticeable increase in $V_{\text {oc }}$ of $26 \mathrm{mV}$ is observed, too, which agrees well with the theoretical results shown in Table 1. The $J_{s c}$ trends for the GalnAs/Ge cells grown on $\mathrm{Ge} \mid \mathrm{Si}$ also match the expected values from the EQE measurements, improving as the absorber is thinned to $2000 \mathrm{~nm}$ thanks to a better carrier collection, but decreasing again for $1000 \mathrm{~nm}$ as the reduction in optical absorption dominates. The $V_{\text {oc }}$ increases for thinner absorbers, but with quantitative variations (up to almost $100 \mathrm{mV}$ ) exceeding the theoretical predictions $(\sim 23 \mathrm{mV})$ for standard $\mathrm{Ge}$ substrates, given the much worse material quality obtained on the Ge|Si templates. In addition, the achievement of a better material quality in thinner layers, as observed in the EQE responses and discussed before in this section, might contribute to this effect too. The $V_{\text {oc }}$ difference between the thin GalnAs subcells grown on $\mathrm{Ge} \mid \mathrm{Si}$ and on $\mathrm{Ge}(218 \mathrm{mV})$ agrees with previously reported results using GaAsP/Si templates with similar TDD [10]. 


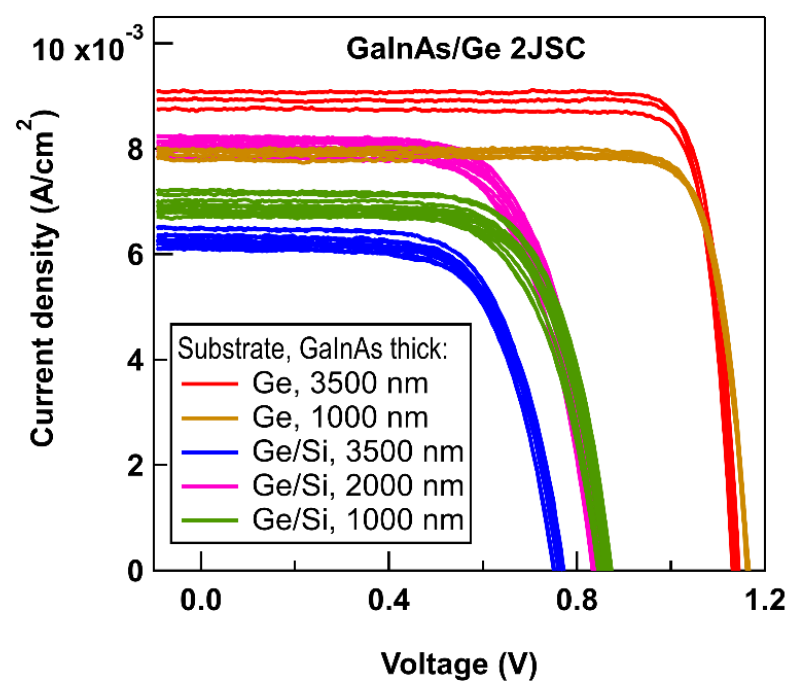

Figure 4. Light J-V curves of the lattice-matched GalnAs (1\% In)/Ge 2JSC grown using standard Ge and virtual Ge|Si substrates, for different thicknesses of the GalnAs absorber layer. The irradiance was set by using a GaAs reference cell and filtering the photons energies above $700 \mathrm{~nm}$, as done for the calculation of the $\mathrm{J}_{\mathrm{sc}}$ from the EQE listed in Table 1.

\begin{tabular}{|c|c|c|c|c|c|}
\hline Substrate & Subcell & $\begin{array}{c}\text { Base thickness } \\
(\mu \mathrm{m})\end{array}$ & $\% \ln$ & $\begin{array}{l}\text { Subcell } \\
V_{o c}(V)\end{array}$ & $\begin{array}{l}\text { Subcell } \\
W_{\text {oc }}(V)\end{array}$ \\
\hline $\mathrm{Ge}$ & \multirow{2}{*}{$\mathrm{Ge}$} & 175 & - & 0.220 & 0.450 \\
\hline $\mathrm{Ge} \mid \mathrm{Si}$ & & 3 & - & 0.140 & 0.530 \\
\hline \multirow{2}{*}{$\mathrm{Ge}$} & \multirow{6}{*}{ GalnAs } & 3.5 & 1 & 0.918 & 0.472 \\
\hline & & 1.0 & 1 & 0.944 & 0.446 \\
\hline \multirow{4}{*}{$\mathrm{Ge} \mid \mathrm{Si}$} & & 3.5 & 1 & 0.622 & 0.768 \\
\hline & & 2.0 & 1 & 0.702 & 0.688 \\
\hline & & 1.0 & 1 & 0.726 & 0.664 \\
\hline & & 1.0 & 6.7 & 0.560 & 0.740 \\
\hline
\end{tabular}

Table 3. Experimental $\mathrm{V}_{\text {oc }}$ of the $\mathrm{Ge}$ and GalnAs subcells presented along this work, obtained from the J-V curves shown in Figure 4 (for GalnAs with $1 \% \mathrm{In}$ ) and Figure 7 (for GalnAs with $6.7 \%$ In). For the GalnAs subcells, it is obtained by using the $\mathrm{V}_{\text {oc }}$ of the GalnAs/Ge 2JSC and subtracting the voltage of the Ge subcell in each case. The $V_{\text {oc }}$ values used are the average for the samples measured. The $W_{o c}$ is the difference between the bandgap and the $\mathrm{V}_{\text {oc }}$ of the subcell.

Therefore, we have shown that drastically thinning the base layer of GalnAs subcell grown on Ge|Si substrates down to $1000 \mathrm{~nm}$ eliminates the formation of macroscopic cracks and recovers its performance by a significant factor. The J-V curve performance metrics of the GalnAs subcell are still poor, given the high defect density of the Ge|Si templates used, and the unexpected formation of misfit dislocations. Improving the GalnAs material quality by using lower TDD substrates is a priority, but in the event that the high quality material grown on standard Ge substrates could not be attained, thinning the subcells will aid not only in reducing cracking but also in recovering the $\mathrm{V}_{\mathrm{oc}}$. 


\subsection{Effect of reducing the bandgap.}

Reducing the bandgap of the GalnAs subcell should allow to reduce its thickness while preserving the current in the 3JSC, at the cost of some voltage loss, as shown in Section 3. In order to reduce the GalnAs base layer to $1000 \mathrm{~nm}$, the indium content has to be increased to $\sim 8 \%$, with a lattice mismatch to the substrate of $\sim 0.5 \%$. This lattice constant transition can be achieved using a compositionally graded buffer (CGB). However, the CGB adds thickness to the semiconductor structure, defeating the original objective of thinning the 3JSC solar cell. Therefore, we have used a CGB design with a minimum increase in the thickness by integrating it in the overbuffer layer grown on top of the GalnP nucleation layer (see Figure 1). This overbuffer, typically $500 \mathrm{~nm}$ of GalnAs, is used to separate the Ge substrate from the active III$\checkmark$ layers and prevent the effect of Ge solid state diffusion reaching active layers [36]. The first CGBs implemented had the same thickness but it was found difficult to attain a proper strain relaxation. To improve it, a $250 \mathrm{~nm}$ overshoot layer with a higher In content than the target was added to the structure, as shown in Figure 5. The TJ and BSF layers also play the role of stepback layer in usual CGB structures. A negligible residual strain in the absorber GalnAs layer was achieved, as corroborated by the HRXRD reciprocal space maps taken, shown in Figure 5. As can be seen, the CGB designed does not follow a linear grading, but uses a step jump at the beginning to enhance earlier relaxation [37]. With this CGB an In composition of $6.7 \%$ was achieved and was used to demonstrate the concept. Further fine tuning of this CGB adjusting the In content can be easily achieved, if required.
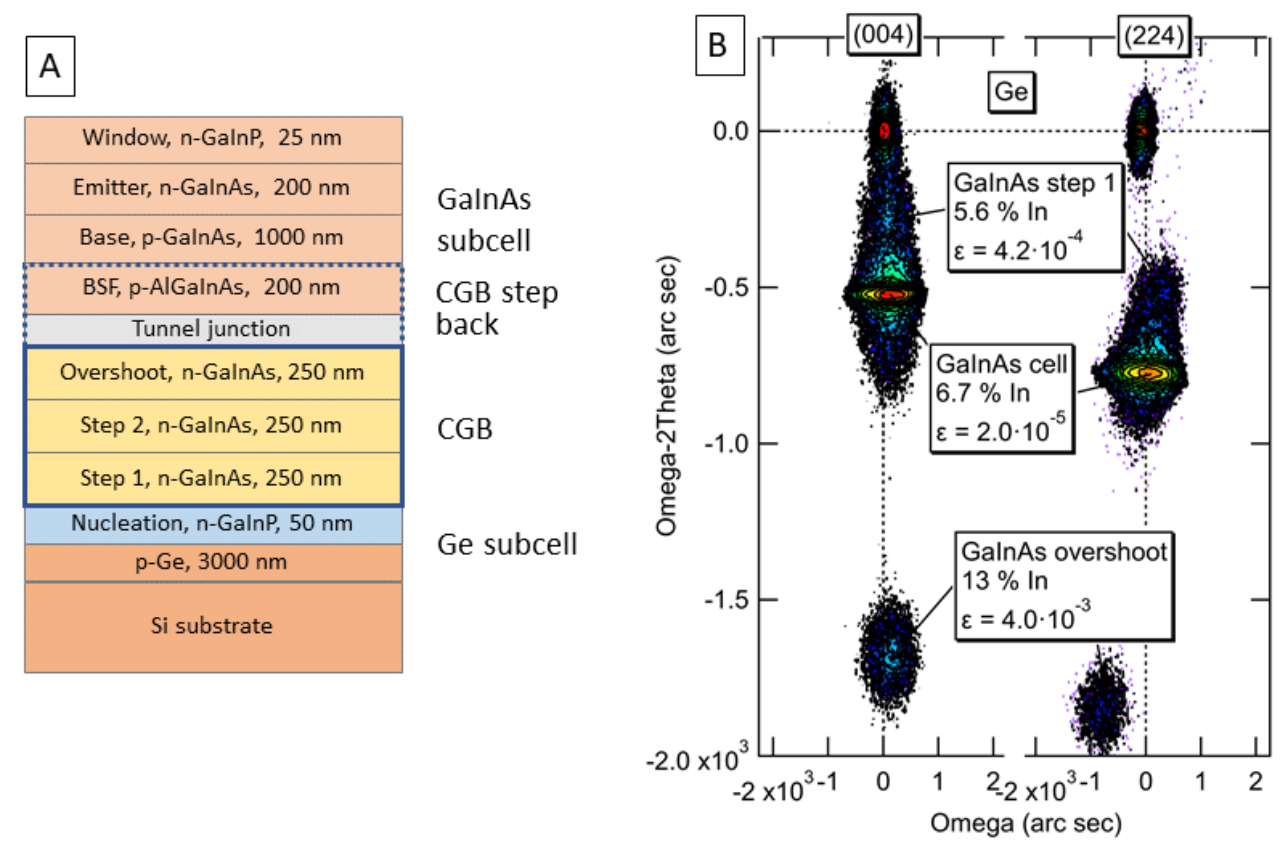

Figure 5. A: structure of a metamorphic GalnAs $(6.7 \% \mathrm{In}) / \mathrm{Ge} 2 \mathrm{JSC}$ including a CGB that replaces the overbuffer layer. B. symmetric and asymmetric RSM taken to measure the lattice constants and derive the residual strain $(\varepsilon)$ and composition of the layers in the CGB and GalnAs cell grown on Ge.

Figure 6 shows the surface of the CGB + GalnAs subcell structures under the Nomarski microscope. No visible cracks can be seen, and the expected crosshatch from the growth with relaxation of the CGB is present. The EQE of the cells with standard and increased In content are shown also in Figure 6 . The cut-off energy increase $(\sim 88 \mathrm{meV})$ agrees with the change of the In content from $1 \%$ to $6.7 \%$ in the GalnAs absorber. The fit to the EQE for this case (solid line) was achieved using a lower electron diffusion length in the base layer than in the case of the same cell thickness but $1.0 \% \mathrm{In}$, as detailed in Table 2 . This lower material quality is attributed to additional TD and roughness introduced during the relaxation of the CGB structure. 

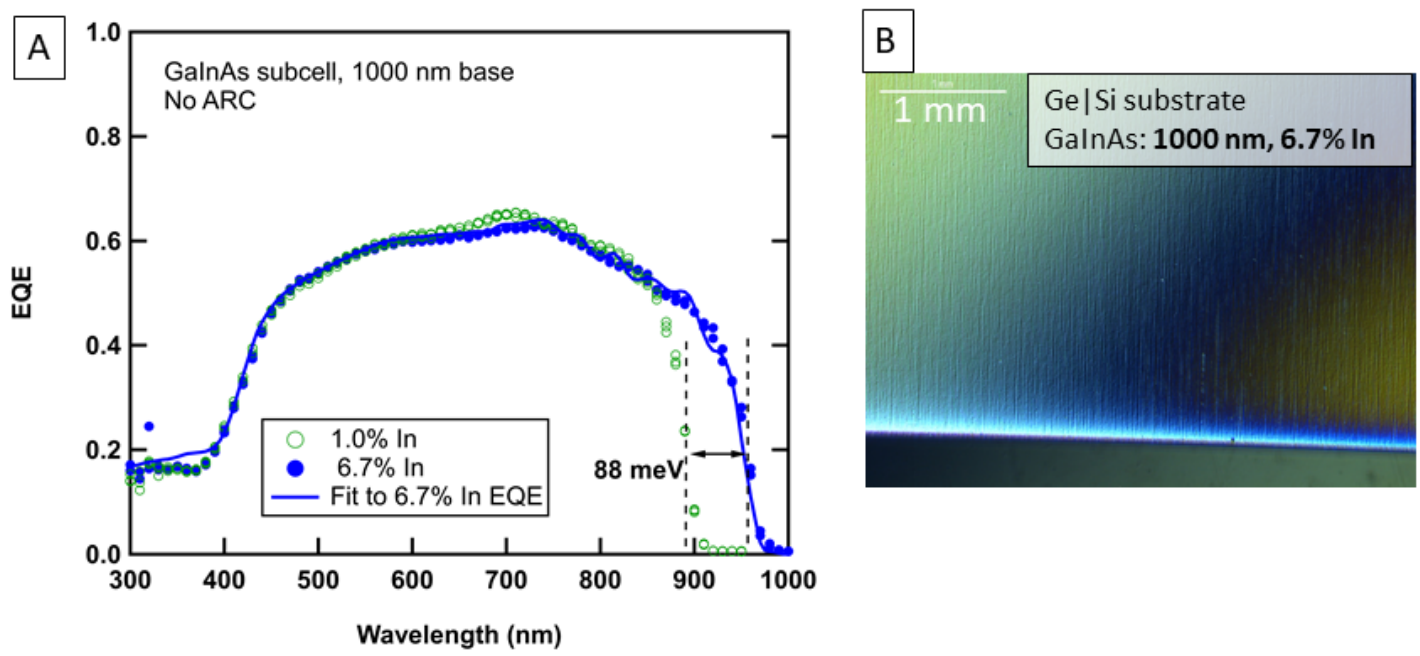

Figure 6. B: Nomarski microscope image of the as-grown surface of metamorphic $\mathrm{GalnAs}(6.7 \% \ln ) / \mathrm{Ge}$ 2JSC on Ge|Si. A: measured EQE of the GalnAs cells grown on Ge|Si with $1 \%$ and $6.7 \%$ In content, and $1000 \mathrm{~nm}$ thickness in both cases. The solid line is the fit to the EQE of the $6.7 \%$ In GalnAs cell.

Light J-V curves of these cells are shown in Figure 7, again for a statistically significant number of devices. The expected increase in $\mathrm{J}_{\mathrm{sc}}$ is observed for the cells with higher In content, but the $\mathrm{V}_{\text {oc }}$ decrease (166 mV, see Table 2 ) is higher than corresponding to the lower bandgap ( $88 \mathrm{mV}$ ). Therefore, these J-V curves demonstrate functional thin and crack-free 2JSC, with a $J_{s c}$ approaching the values for thick GalnAs cells grown on standard Ge substrates. The electronic quality and $V_{o c}$ must be improved to obtain the targeted device performance. Using Ge|Si virtual substrates with reduced TDD will contribute largely to this objective.

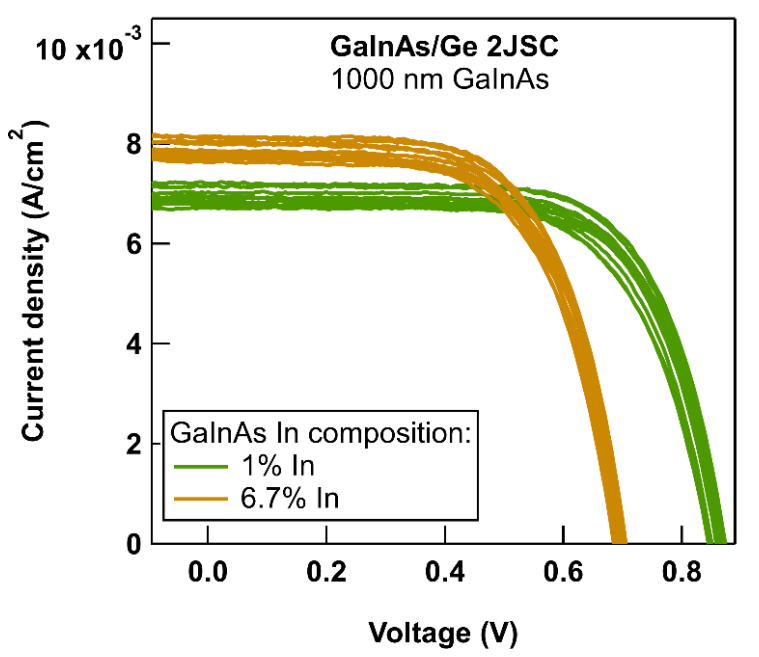

Figure 7. Light J-V curves of the GalnAs/Ge $2 \mathrm{JSC}$ cells grown on Ge|Si with $1 \%$ and $6.7 \%$ In content, and $1000 \mathrm{~nm}$ thickness GalnAs.

\section{GaInP/GalnAs/Ge|Si triple-junction solar cell results.}

The approach of thinning and decreasing the bandgap of the GalnAs subcell makes sense if current matching in the 3JSC can be preserved by either thinning the GalnP top cell or using AlGalnP to raise its bandgap. However, at this stage of development we have not attempted to optimize the top cell yet. The 3JSC implementations so far are not intended to achieve a high efficiency, but to demonstrate a crack-free structure, anticipate potential component integration issues and assess the performance obtained. 
During the development iterations to build a functional 3JSC with thinned and higher In content GalnAs subcell, the compositions of the layers above this subcell had to be adjusted to be lattice-matched. This included the sensitive high bandgap tunnel junction, which uses a quantum-well to improve the tunneling probability [38] and resulted to work adequately for the new compositions. Besides, no significant cracking was observed in the as-grown 3JSC structures, as shown in Figure 8. In addition to the crossh-hatch from the metamorphic growth, macroscopic defects can be observed in these Nomarski images, which are caused by particles formed during dicing of the Ge|Si virtual substrates prior to growth. These deffects resulted in some devices being shunted, which were discarded. The fact that no cracking was observed in these 3JSC samples was surprising since, with a total thickness of $\sim 6 \mu \mathrm{m}$, they are slightly above the expected critical thickness for the formation of cracks [9]. In fact, the GalnAs/Ge cells with such thicknesses showed cracks, as presented in previous sections. The absence of cracks in the 3JSC structures can be explained by the effect of the residual compressive strain in the CGB and GalnAs subcells, which can partially compensate the tensile strain during cooldown. This effect might provide advantage by intentionally modulating the residual compressive strain in the GalnAs subcell and CGBs, which we are investigating currently. After processing of the epistructures into solar cell devices, some cracks appeared, although still is a much lower density than in the thick GalnAs/Ge cells, as illustrated in Figure 8. This means that some residual strain is locked in the structure and is released during manipulation for the processing. We are currently investigating the effect of this residual strain on the reliability of the devices, and ways to minimize it by redesigning the CGB. Further thinning of the structure will, of course, be helpful for this purpose. Ge|Si substrates with thinner Ge layers will be tested in the near term.

Figure 8 shows the EQE of the top and middle cells in the 3JSC, compared to the case of a typical design on standard Ge substrates. The Ge bottom cell is not shown because it was not possible to measure it due to its leaky behaviour similarly as already reported for Ge|Si substrates with $5 \mu \mathrm{m}$ Ge layer [19], [20]. As compared to the standard design, the GalnP top cell shows the expected shift in absorption edge in both the absorber material and window layer as a result of the higher In content. The EQE of the GalnAs subcell is similar to that shown for the GalnAs/Ge 2JSC in Figure 6 but filtered by the GaInP top subcell and upper tunnel junction.

The potential of this solar cell design to attain the required $J_{s c}$ once the top cell is appropriately designed was analyzed. Using the same minority carrier parameters as obtained from the fits to the experimental data, the EQE of the 3JSC was calculated for a top cell with the same bandgap as in the standard Ge substrate case (i.e., using AlGalnP) and optimized thickness, and with an anti-reflection coating (ARC) based on $\mathrm{MgF}_{2}$ and $\mathrm{ZnS}$ (see Figure 8). It is found that current matching at $15.3 \mathrm{~mA} / \mathrm{cm}^{2}$ is attainable under the AM1.5G solar spectrum. Note that this $\mathrm{J}_{\mathrm{sc}}$ is slightly higher than predicted by our model in Section 3 , which indicates that In compositions below 7\% in practical $1000 \mathrm{~nm}$ thick GalnAs subcell can be enough to attain the same $J_{s c}$ as in the standard 3JSC. A thinned GalnP the top cell could also serve to achieve current matching, but with the voltage penalty commented before. 


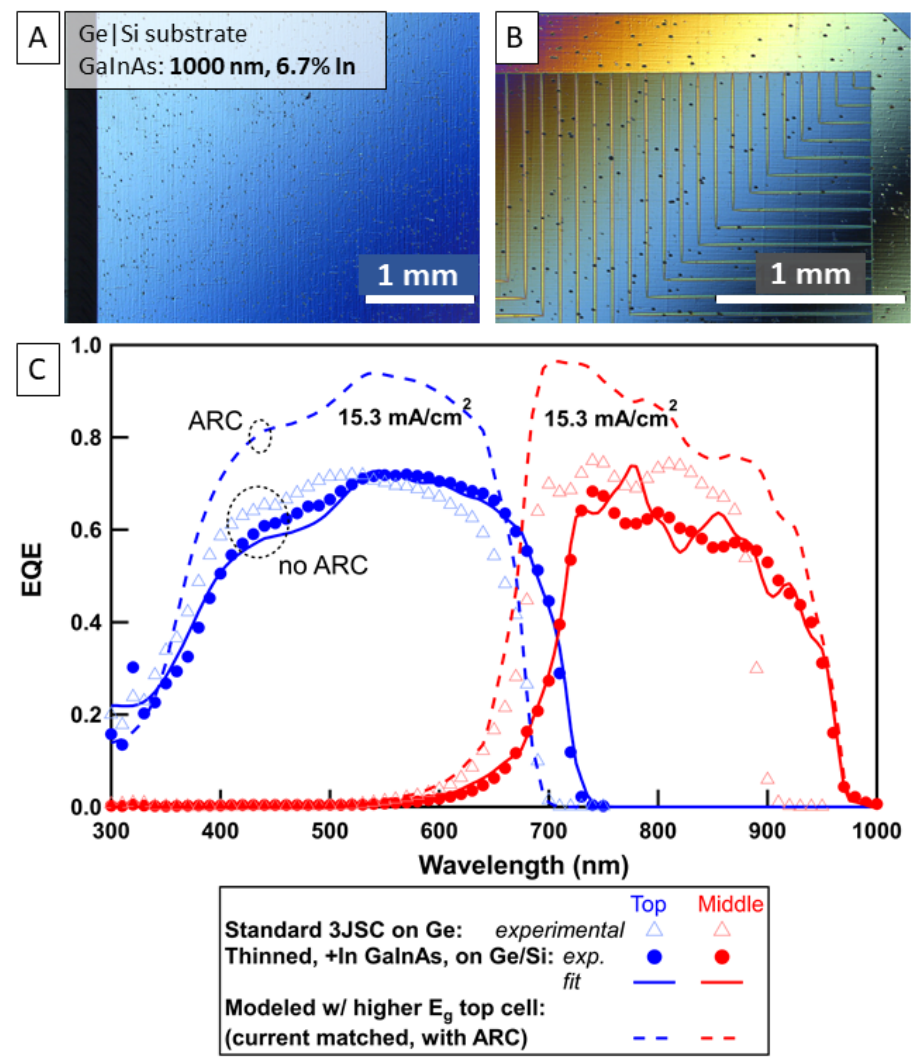

Figure 8. A-B: Nomarski microscope images of the 3JSC on Ge|Si right after growth (A) and after processing of the solar cell devices (B). $\underline{\mathrm{C}}$ : EQE of the top and middle cells of the 3JSC implemented. The symbols correspond to the experimental results for the standard 3JSC on Ge substrates (empty triangles) and the 3JSC with thinned and $6.7 \%$ In content GalnAs middle cell on Ge|Si virtual substrate (filled circles). The solid line is a fit to the latter. The dashed line corresponds to a projection of the EQE obtained by using the fitted data but increasing the bandgap of the top cell and adding an optimized $\mathrm{MgF}_{2} / \mathrm{ZnS}$ ARC.

Light J-V curves of the 3JSC are shown in Figure 9, compared to the case of standard Ge substrate. Firstly, these J-V curves demonstrate the functionality of the 3JSC developed, with a $J_{s c}$ similar to the standard design. Note that the full $J_{s c}$ increase expected when raising the In content in the GalnAs subcell is limited by the decrease of the bandgap in the GalnP top cell at the same time, which does not allow reaching the $\mathrm{J}_{\mathrm{sc}}$ of the standard 3JSC grown on Ge. Once the top cell bandgap is raised (or it is thinned), the $\mathrm{J}_{\mathrm{sc}}$ of the redesigned 3JSC should match the $\mathrm{J}_{\mathrm{sc}}$ of the standard 3JSC. The $\mathrm{V}_{\mathrm{oc}}$ drop observed has different components. Firstly, a $\mathrm{V}_{\mathrm{oc}}$ drop of $\sim 185 \mathrm{mV}$ is caused by the lower bandgap in the GalnAs and GalnP subcell, as estimated from EL peak measurements. Then, the effect of the TDD on the $V_{\text {oc }}$ of these subcells can be estimated to be around $350 \mathrm{mV}$ [10]. An additional $\mathrm{V}_{\text {oc }}$ drop can be attributed to the lower quality in the $6.7 \%$ In material of the GalnAs subcell discussed before (estimated $78 \mathrm{mV}$ drop), which is probably affecting the GalnP top cell for the remaining of the $V_{o c}$ difference.

These results demonstrate a crack-free as-grown prototype 3JSC on Ge|Si virtual substrate. The final solar cell devices exhibit some cracks, but with promising functionality, illustrating the potential of this approach, as the main goal of this work. At the same time, these results emphasize on the fact that attaining an increased $V_{\text {oc }}$ will require first and foremost using a lower TDD virtual substrate, and improving the epilayer material quality, which is the main goal of our current efforts. 


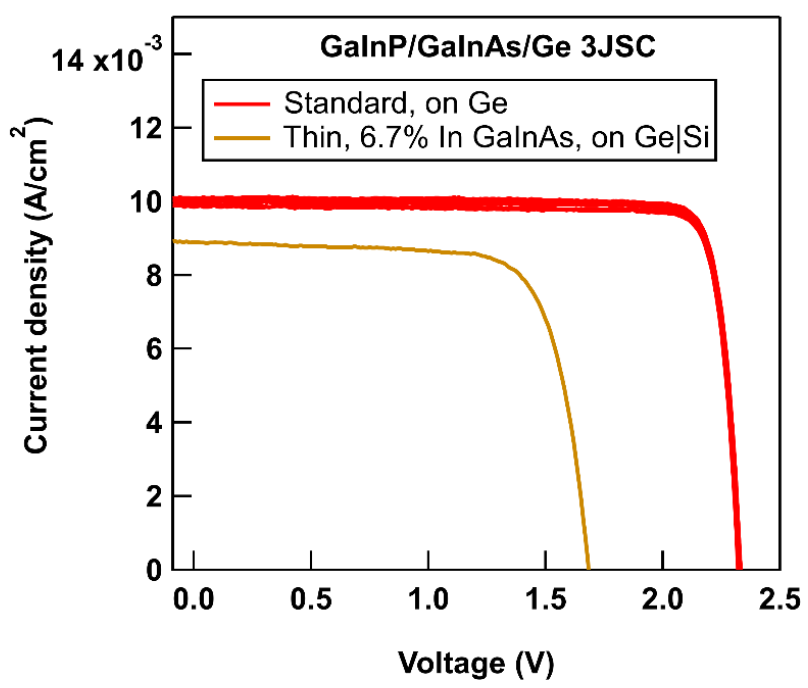

Figure 9. Light J-V measurements of the 3JSC grown on Ge|Si with thin and $6.7 \%$ In GalnAs subcell, compared to the case of a typical design on standard Ge substrate.

\section{Summary and conclusions}

The formation of cracks in GaInP/GalnAs/Ge 3JSC grown on Ge|Si virtual substrates, demonstrated to be a major challenge in our previous works, can be mitigated by thinning the structure, which we have attempted by reducing the thickness of the Ge layer in the Ge|Si template and of the GalnAs middle cell. Our theoretical calculations, based on empirical parameters obtained from standard 3JSC developed previously, indicate that a thin GalnAs middle cell with $1000 \mathrm{~nm}$ base layer and 8\% In composition, with an (Al)GalnP top cell, should allow reproducing the performance of a standard 3JSC with a low $V_{\text {oc }}$ loss of around $3 \%$ at 1 -sun and $2 \%$ for concentrations of 1000 suns. Thinning this junction is predicted to help increasing the $V_{o c}$ through a reduced recombination volume. This is demonstrated experimentally with even higher $\mathrm{V}_{\text {oc }}$ increases than predicted theoretically in our GalnAs cells grown on $\mathrm{Ge} \mid \mathrm{Si}$, since they exhibit higher recombination currents than the cells grown on standard Ge substrates used for the modeling. Moreover, these thinned structures do not exhibit cracking. A higher In content up to $6.7 \%$ in the GalnAs subcell is obtained experimentally by means of a CGB structure that replaces the usual overbuffer layer and attains a low residual strain. This thin metamorphic $6.7 \%$ In cell achieves $J_{s c}$ values similar as in cells grown lattice-matched to Ge. However, the metamorphic growth on the Ge|Si templates is found to result in an additional voltage loss, probably due to an increased TDD generated during metamorphic growth on the highly dislocated Ge|Si substrates. Full 3JSC including this GalnAs subcell are also implemented to demonstrate the concept and anticipate integration issues. Despite the total 3JSC thickness is slightly above the expected critical thickness for crack propagation, the effect of the compressive strain in the CGB used appears to mitigate the formation of cracks in the as-grown devices. In this way, we demonstrate the potential of this design concept with functional 3JSC solar cell devices that exhibit an adequate carrier collection in the top and middle cells. Once the top cell is thinned or its bandgap is raised, these solar cells should match the $\mathrm{J}_{\mathrm{sc}}$ of standard 3JSC grown on Ge. However, the growth on Ge|Si templates with high TDD, possibly exacerbated by the CGB, affects the quality of the top and middle cell absorber layers, giving rise to a large $\mathrm{V}_{\text {oc }}$ loss. Further development beyond the demonstration of the concept intended for this work relies on the ability to improve the material quality and lowering the recombination currents, by using new Ge|Si templates with lower TDD and redesigning the CGB used to minimize the introduction 
of additional dislocations. Once this is attained, the efficiency achievable is only about 2-3\% lower than in the standard 3JSC grown on Ge substrates due to the lower voltage in the GalnAs subcell with high In content. To determine the economic worthiness of this approach, this efficiency loss will have to be assessed against the economic benefits of using Ge|Si virtual substrates, such as the lower Ge consumption and potential cost, as well as other technological advantages such as the possibility of enabling high throughput ELO processes by means of embedded porous layers in the Si substrate.

\section{ACKNOWLEDGEMENTS}

We acknowledge technical support from J. Bautista and L. Cifuentes for device processing. Funding from AEI (project RTI2018-094291-B-I00) is gratefully acknowledged. M. Hinojosa is funded by the Spanish MECD through a FPU grant (FPU-15/03436), I. García is funded by the Spanish Programa Estatal de Promoción del Talento y su Empleabilidad through a Ramon y Cajal grant (RYC-2014- 15621) and S. Dadgostar was funded by JCYL and FEDER (Project VA283P18).

\section{REFERENCES}

[1] K. Hayashi, T. Soga, H. Nishikawa, T. Jimbo, and M. Umeno, "MOCVD growth of GaAsP on Si for tandem solar cell application," in Proceedings of 1994 IEEE 1st World Conference on Photovoltaic Energy Conversion - WCPEC (A Joint Conference of PVSC, PVSEC and PSEC), Dec. 1994, vol. 2, pp. 1890-1893 vol.2, doi: 10.1109/WCPEC.1994.520736.

[2] T. J. Grassman, D. J. Chmielewski, S. D. Carnevale, J. A. Carlin, and S. A. Ringel, "GaAs $0.75 \mathrm{P}_{0.25} / \mathrm{Si}$ Dual-Junction Solar Cells Grown by MBE and MOCVD," IEEE J. Photovolt., vol. 6, no. 1, pp. 326-331, Jan. 2016, doi: 10.1109/JPHOTOV.2015.2493365.

[3] J. F. Geisz, J. M. Olson, M. J. Romero, C. s. Jiang, and A. G. Norman, "Lattice-mismatched GaAsP Solar Cells Grown on Silicon by OMVPE," in 2006 IEEE 4th World Conference on Photovoltaic Energy Conference, May 2006, vol. 1, pp. 772-775, doi: 10.1109/WCPEC.2006.279570.

[4] K. N. Yaung, M. Vaisman, J. Lang, and M. L. Lee, "GaAsP solar cells on GaP/Si with low threading dislocation density," Appl. Phys. Lett., vol. 109, no. 3, p. 032107, Jul. 2016, doi: 10.1063/1.4959825.

[5] M. R. Lueck, C. L. Andre, A. J. Pitera, M. L. Lee, E. A. Fitzgerald, and S. A. Ringel, "Dual junction GalnP/GaAs solar cells grown on metamorphic SiGe/Si substrates with high open circuit voltage," IEEE Electron Device Lett., vol. 27, no. 3, pp. 142-144, Mar. 2006, doi: 10.1109/LED.2006.870250.

[6] S. A. Ringel, J. A. Carlin, C. L. Andre, M. K. Hudait, M. Gonzalez, D. M. Wilt, E. B. Clark, P. Jenkins, D. Scheiman, A. Allerman, E. A. Fitzgerald, and C. W. Leitz, "Single-junction InGaP/GaAs solar cells grown on Si substrates with SiGe buffer layers," Prog. Photovolt. Res. Appl., vol. 10, no. 6, pp. 417-426, 2002, doi: 10.1002/pip.448.

[7] A. J. Pitera, J. Hennessy, A. C. Malonis, E. A. Fitzgerald, and S. A. Ringel, "Monolithically integrated thin film III-V/Si solar panel on wafer for active power management," in 2011 37th IEEE Photovoltaic Specialists Conference, Jun. 2011, pp. 003703-003706, doi: 10.1109/PVSC.2011.6185955.

[8] K. J. Schmieder, A. Gerger, M. Diaz, Z. Pulwin, C. Ebert, A. Lochtefeld, R. Opila, and A. Barnett, "Analysis of tandem III-V/SiGe devices grown on Si," in 2012 38th IEEE Photovoltaic Specialists Conference, Jun. 2012, pp. 000968-000973, doi: 10.1109/PVSC.2012.6317764. 
[9] V. K. Yang, M. Groenert, C. W. Leitz, A. J. Pitera, M. T. Currie, and E. A. Fitzgerald, "Crack formation in GaAs heteroepitaxial films on $\mathrm{Si}$ and SiGe virtual substrates," J. Appl. Phys., vol. 93, no. 7, pp. 3859-3865, Mar. 2003, doi: 10.1063/1.1558963.

[10] M. Feifel, D. Lackner, J. Ohlmann, J. Benick, M. Hermle, and F. Dimroth, "Direct Growth of a GalnP/GaAs/Si Triple-Junction Solar Cell with 22.3\% AM1.5g Efficiency," Sol. RRL, vol. 3, no. 12, p. 1900313, 2019, doi: https://doi.org/10.1002/solr.201900313.

[11] H.-C. Luan, D. R. Lim, K. K. Lee, K. M. Chen, J. G. Sandland, K. Wada, and L. C. Kimerling, "High-quality Ge epilayers on Si with low threading-dislocation densities," Appl. Phys. Lett., vol. 75, no. 19, pp. 2909-2911, Nov. 1999, doi: 10.1063/1.125187.

[12] K. H. Lee, S. Bao, B. Wang, C. Wang, S. F. Yoon, J. Michel, E. A. Fitzgerald, and C. S. Tan, "Reduction of threading dislocation density in Ge/Si using a heavily As-doped Ge seed layer," AIP Adv., vol. 6, no. 2, p. 025028, Feb. 2016, doi: 10.1063/1.4943218.

[13] G. Zhou, K. H. Lee, D. H. Anjum, Q. Zhang, X. Zhang, C. S. Tan, and G. (Maggie) Xia, "Impacts of doping on epitaxial germanium thin film quality and Si-Ge interdiffusion," Opt. Mater. Express, vol. 8, no. 5, pp. 1117-1131, May 2018, doi: 10.1364/OME.8.001117.

[14] R. Ginige, B. Corbett, M. Modreanu, C. Barrett, J. Hilgarth, G. Isella, D. Chrastina, and H. von Känel, "Characterization of Ge-on-Si virtual substrates and single junction GaAs solar cells," Semicond. Sci. Technol., vol. 21, no. 6, pp. 775-780, Apr. 2006, doi: 10.1088/02681242/21/6/011.

[15] T. W. Kim, B. R. Albert, L. C. Kimerling, and J. Michel, "InGaP solar cell on Ge-on-Si virtual substrate for novel solar power conversion," J. Appl. Phys., vol. 123, no. 8, p. 085111, Feb. 2018, doi: 10.1063/1.5018082.

[16] Y. Wang, Z. Ren, M. Thway, K. Lee, S. F. Yoon, I. M. Peters, T. Buonassisi, E. A. Fizgerald, C. S. Tan, and K. H. Lee, "Fabrication and characterization of single junction GaAs solar cells on Si with As-doped Ge buffer," Sol. Energy Mater. Sol. Cells, vol. 172, pp. 140-144, Dec. 2017, doi: 10.1016/j.solmat.2017.07.028.

[17] Y. A. Bioud, A. Boucherif, M. Myronov, A. Soltani, G. Patriarche, N. Braidy, M. Jellite, D. Drouin, and R. Arès, "Uprooting defects to enable high-performance III-V optoelectronic devices on silicon," Nat. Commun., vol. 10, no. 1, Art. no. 1, Sep. 2019, doi: 10.1038/s41467-019-12353-9.

[18] S. Oh, D. H. Jun, K. W. Shin, I. Choi, S. H. Jung, J. Choi, W. Park, Y. Park, and E. Yoon, "Control of Crack Formation for the Fabrication of Crack-Free and Self-Isolated High-Efficiency Gallium Arsenide Photovoltaic Cells on Silicon Substrate," IEEE J. Photovolt., vol. 6, no. 4, pp. 1031-1035, Jul. 2016, doi: 10.1109/JPHOTOV.2016.2566887.

[19] I. García, M. Hinojosa, I. Lombardero, L. Cifuentes, I. Rey-Stolle, C. Algora, H. Nguyen, Edwards, S, Morgan, A, and Johnson, A, "Ge virtual substrates for high efficiency III-V solar cells: applications, potential and challenges," in 46th IEEE PVSC, Chicago, USA, 2019, pp. 1444-1451, doi: 10.1109/PVSC40753.2019.8980914.

[20] I. García, I. Rey-Stolle, M. Hinojosa, I. Lombardero, L. Cifuentes, C. Algora, H. Nguyen, A. Morgan, and A. Johnson, "Space III-V multijunction solar cells on Ge/Si virtual substrates," in 2019 European Space Power Conference (ESPC), Juan-Les-Pins, France, Oct. 2019, pp. 16, doi: 10.1109/ESPC.2019.8932026.

[21] W. Guter, F. Dunzer, L. Ebel, K. Hillerich, W. Köstler, T. Kubera, M. Meusel, B. Postels, and C. Wächter, "Space Solar Cells - 3 G30 and Next Generation Radiation Hard Products," in E3S Web of Conferences, 2017, vol. 16, p. 03005, doi: 10.1051/e3sconf/20171603005.

[22] E. Centurioni, "Generalized matrix method for calculation of internal light energy flux in mixed coherent and incoherent multilayers," Appl. Opt., vol. 44, no. 35, pp. 7532-7539, Dec. 2005, doi: 10.1364/AO.44.007532.

[23] M. Ochoa Gómez, "TCAD Modelling, simulation and characterization of III-V multijunction solar cells," PhD, E.T.S.I. Telecomunicación (UPM), 2018. 
[24] M. A. Steiner, J. F. Geisz, I. García, D. J. Friedman, A. Duda, and S. R. Kurtz, "Optical enhancement of the open-circuit voltage in high quality GaAs solar cells," J. Appl. Phys., vol. 113, no. 12, p. 123109, Mar. 2013, doi: 10.1063/1.4798267.

[25] L. Barrutia, I. Garcia, E. Barrigón, E. Barrigón, M. Ochoa, I. Lombardero, M. Hinojosa, P. Cano, J. Bautista, L. Cifuentes, I. Rey-Stolle, and C. Algora, "Development of the Lattice Matched GaInP/GaInAs/Ge Triple Junction Solar Cell with an Efficiency Over 40\%," in 2018 Spanish Conference on Electron Devices (CDE), Nov. 2018, pp. 1-4, doi: 10.1109/CDE.2018.8596996.

[26] P. Caño, M. Hinojosa, L. Cifuentes, H. Nguyen, A. Morgan, D. Fuertes, I. García, A. Johnson, and I. Rey-Stolle, "Hybrid III-V/SiGe solar cells on Si substrates and porous Si substrates," in 46th IEEE PVSC, Chicago, USA, 2019, pp. 2513-2518, doi: 10.1109/PVSC40753.2019.8981138.

[27] W. Guter, J. Schöne, S. P. Philipps, M. Steiner, G. Siefer, A. Wekkeli, E. Welser, E. Oliva, A. W. Bett, and F. Dimroth, "Current-matched triple-junction solar cell reaching $41.1 \%$ conversion efficiency under concentrated sunlight," Appl. Phys. Lett., vol. 94, no. 22, p. 223504, Jun. 2009, doi: 10.1063/1.3148341.

[28] E. E. Perl, J. Simon, J. F. Geisz, W. Olavarria, M. Young, A. Duda, D. J. Friedman, and M. A. Steiner, "Development of High-Bandgap AIGalnP Solar Cells Grown by Organometallic Vapor-Phase Epitaxy," IEEE J. Photovolt., vol. 6, no. 3, pp. 770-776, May 2016, doi: 10.1109/JPHOTOV.2016.2537543.

[29] J. F. Geisz, R. M. France, K. L. Schulte, M. A. Steiner, A. G. Norman, H. L. Guthrey, M. R. Young, T. Song, and T. Moriarty, "Six-junction III-V solar cells with $47.1 \%$ conversion efficiency under 143 Suns concentration," Nat. Energy, vol. 5, no. 4, Art. no. 4, Apr. 2020, doi: 10.1038/s41560-020-0598-5.

[30] J. I. Pankove, Optical Processes in Semiconductors, 2nd Revised ed. edition. Mineola NY: Dover Publications, 2010.

[31] M. A. Steiner, J. F. Geisz, I. García, D. J. Friedman, A. Duda, W. J. Olavarria, M. Young, D. Kuciauskas, and S. R. Kurtz, "Effects of Internal Luminescence and Internal Optics on $\backslash$ bf oc and Ibf sc of III-V Solar Cells," IEEE J. Photovolt., vol. 3, no. 4, pp. 1437-1442, Oct. 2013, doi: 10.1109/JPHOTOV.2013.2278666.

[32] I. Garcia, R. M. France, J. F. Geisz, W. E. McMahon, M. A. Steiner, S. Johnston, and D. J. Friedman, "Metamorphic III-V Solar Cells: Recent Progress and Potential," IEEE J. Photovolt., vol. 6, no. 1, pp. 366-373, Jan. 2016, doi: 10.1109/JPHOTOV.2015.2501722.

[33] N. Jain and M. K. Hudait, "Impact of Threading Dislocations on the Design of GaAs and InGaP/GaAs Solar Cells on Si Using Finite Element Analysis," IEEE J. Photovolt., vol. 3, no. 1, pp. 528-534, Jan. 2013, doi: 10.1109/JPHOTOV.2012.2213073.

[34] E. Barrigón, M. Ochoa, I. García, L. Barrutia, C. Algora, and I. Rey-Stolle, "Degradation of Ge subcells by thermal load during the growth of multijunction solar cells," Prog. Photovolt. Res. Appl., vol. 26, no. 2, pp. 102-111, Feb. 2018, doi: 10.1002/pip.2948.

[35] I. García, M. Ochoa, I. Lombardero, L. Cifuentes, M. Hinojosa, P. Caño, I. Rey-Stolle, C. Algora, A. Johnson, I. Davies, K. H. Tan, W. K. Loke, S. Wicaksono, and S. F. Yoon, "Degradation of subcells and tunnel junctions during growth of GalnP/Ga(In)As/GaNAsSb/Ge 4-junction solar cells," Prog. Photovolt. Res. Appl., vol. 25, no. 11, pp. 887-895, Nov. 2017, doi: 10.1002/pip.2930.

[36] L. Barrutia, I. García, E. Barrigón, M. Ochoa, C. Algora, and I. Rey-Stolle, "Impact of the III$\mathrm{V} / \mathrm{Ge}$ nucleation routine on the performance of high efficiency multijunction solar cells," Sol. Energy Mater. Sol. Cells, vol. 207, p. 110355, Apr. 2020, doi: 10.1016/j.solmat.2019.110355.

[37] I. García, R. M. France, J. F. Geisz, and J. Simon, "Thin, high quality GalnP compositionally graded buffer layers grown at high growth rates for metamorphic III-V solar cell 
applications," J. Cryst. Growth, vol. 393, pp. 64-69, May 2014, doi: 10.1016/j.jcrysgro.2013.10.043.

[38] E. Barrigón, I. García, L. Barrutia, I. Rey-Stolle, and C. Algora, "Highly conductive p++ AlGaAs/n++-GalnP tunnel junctions for ultra-high concentrator solar cells," Prog. Photovolt. Res. Appl., vol. 22, no. 4, pp. 399-404, Apr. 2014, doi: 10.1002/pip.2476. 